\title{
We All Live in a Virtual Submarine
}

0

ur seas and oceans hide a plethora of archaeological sites such as ancient shipwrecks that, over time, are being destroyed through activities such as deepwater trawling and treasure hunting. In 2006, a multidisciplinary team of 11 European institutions established the Venus (Virtual Exploration of Underwater Sites) ${ }^{1}$ consortium to make underwater sites more accessible by generating thorough, exhaustive 3D records for virtual exploration.

Over the past three years, we surveyed several shipwrecks around Europe and investigated advanced techniques for data acquisition using both autonomous and remotely operated vehicles coupled with innovative sonar and photogrammetric equipment. Access to most underwater sites can be difficult and hazardous owing to deep waters. However, this same inhospitable environment offers extraordinary opportunities to archaeologists because darkness, low temperatures, and low oxygen rates are all favorable to preservation.

From a visualization pipeline perspective, this project had two main challenges. First, we had to gather large amounts of raw data from various sources. Then, we had to develop techniques to filter, calibrate, and map the data and then bring it all together into a single accurate visual representation.

\section{Venus Goals and Objectives}

These underwater sites are out of reach to all but a few specially trained archaeologists. Recreating the sites as interactive virtual environments lets both experts and the general public study these important pieces of (disappearing) cultural heritage in a safe, cost-effective, and pedagogical environment.

The Venus project's objectives included

- defining best practices for collecting and storing data from archaeological sites,

- surveying wrecks using remotely operated vehicles (ROVs), and

- developing software tools for visualizing, and immersively interacting with, the collected data.
To help achieve most of these objectives, the project used contemporary computer graphics and visualization techniques in various forms. For example, using an ROV to accurately survey shipwrecks can be complex and difficult for the pilot. However, through real-time visualization and tracking techniques, we can provide the pilot with a real-time $3 \mathrm{D}$ visualization of the ROV accurately positioned in relation to a prerendered 3D bathymetric seabed (color coded according to depth). This visualization might also include the ROV's "eyes" via a video feed from specially mounted cameras on the submersible. We can further augment the visualization to provide a "snail trail" over areas already photographed and scanned. This both facilitates identification of areas to be surveyed and identifies a possible exit route in case the ROV umbilical becomes snagged.

The project's end users are archaeologists and the general public. Here, we focus on visualization for (and dissemination to) the general public. Archaeologists aren't concerned with plant life and underwater-lighting effects; they need a clear vision of the whole site (sometimes without the seabed) and multiple interactions with the artifact. The general public, however, want to experience realistic virtual dives down to accurate visualizations of archaeological sites as though they were actually piloting the submersible.

\section{Pianosa}

Part of the project involved surveying the underwater archaeological site off the island of Pianosa, in the Tuscan archipelago. This site, discovered in 1989 by divers Giuseppe Adriani and Paolo Vaccari, is near the Scoglio della Scola (a large rock), off the island's east coast at a depth of $35 \mathrm{~m}$. At the site are about 100 amphorae (ancient jars with two handles typically used to transport oil or wine) of different origins and epochs. Figure 1 shows a multibeam-sonar survey of the site.

The Pianosa survey involved significant interdisciplinary collaboration and focused on collecting georeferenced optical data for photogrammetric reconstruction. The Venus team determined an
Paul

Chapman

Glasgow

School of Art

\section{Kim Bale \\ University of \\ Hull}

Pierre Drap

Laboratoire

des Sciences de l'Information

et des

Systèmes,

Marseille 


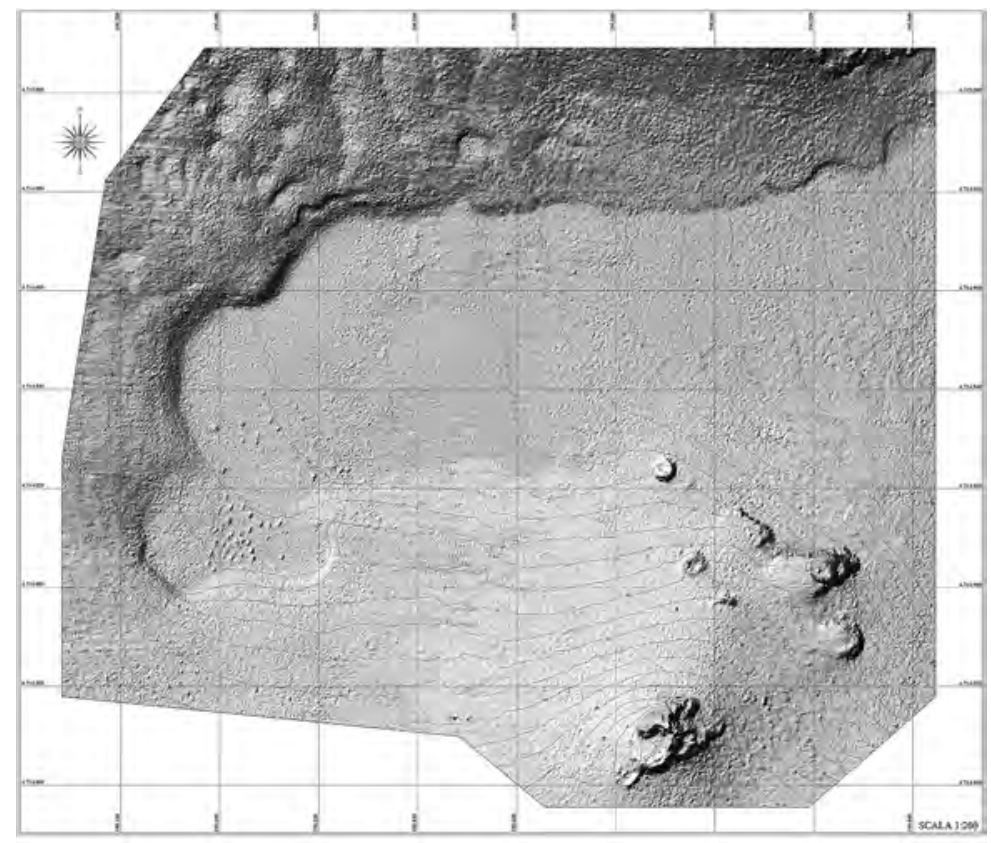

Figure 1. A multibeam-sonar image of the underwater archaeological site near the island of Pianosa, off the west coast of Italy. The site contains approximately 100 amphorae of different origins and epochs.

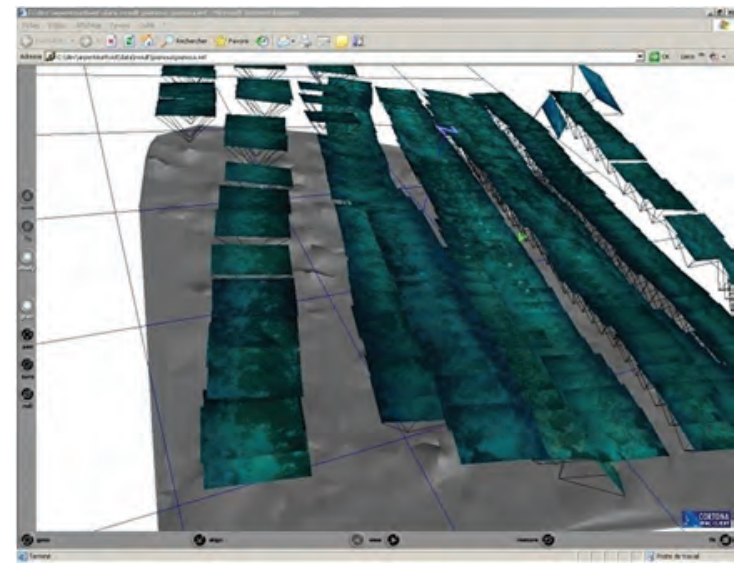

Figure 2. Oriented photographs visualized in VRML with the nontextured seabed obtained using photogrammetry. We used this unified data to create our 3D virtual environment.

area to be surveyed around the site and prepared it with 2 -m scale bars and 15 cement block markers to define a control point calibration network for the ROV to measure. The data was collected by divers from the French National Centre for Scientific Research, a Venus partner, and by Integrated Systems for Marine Environment, which provided a Phantom S2 ROV for georeferencing the photogrammetric data.

\section{Data Acquisition}

We generated the photogrammetric survey using hundreds of overlapping photographs. We measured homologous points on the photographs to orient all the photographs into a local reference system. We then used the cement block positions provided by the ROV navigation data that were consistent with bathymetric-sonar data.

Figure 2 shows how we used visualization and photogrammetric tools to help unify the data sets. In this example, we used the Arpenteur photogrammetric and visualization toolbox ${ }^{2}$ to generate and visualize a 3D model of the seabed using the corresponding overlapping and superimposed photographs. We also gathered more extensive seabed terrain data, using multibeam bathymetric sonar.

\section{Modeling the Amphorae}

The immersive visualization required 3D geometric modeling of the amphorae, which was driven by expert (archaeological) knowledge. We implemented the modeling procedure in Java and connected it to Arpenteur. The procedure is revisable over time, allowing reprocessing or augmentation as new data becomes available. We stored the resulting models in a repository database for further research and for visualization. Figure 3 shows a range of computer-generated 3D amphorae models used in the project.

\section{The 3D Modeling Process}

The process consisted of two steps: developing theoretical models and implementing a decision support system.

The theoretical models. Amphora classification in archaeology relies heavily on dimension information related to specific object features-for example, the neck. In providing a theoretical model for a specific amphora class, it makes sense to measure these features directly on actual artifacts from the site. At the Pianosa site, the divers carefully removed (and later returned) six amphorae, which we used as a paradigm to define the amphorae's theoretical models. Because these six don't account for all the classes of amphorae at the site, we complemented the direct observations of the finds with drawings and information from archival data. For example, we modeled type Gauloise 3 amphorae according to the typology presented by the University of York Archaeological Data Service (http://ads.ahds. ac.uk/catalogue/archive/amphora_ahrb_2005/ details.cfm?id=135).

In defining the theoretical model, the diversity of the objects handled by the archaeologists and their surfaces' geometric complexity led us to search for stable morphological characteristics of the objects from which we could take diagnostic 


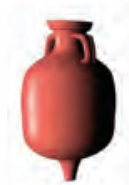

Haltern 70

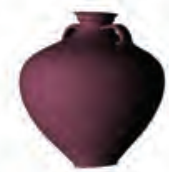

Gauloise 3

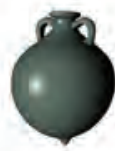

Dressel 20

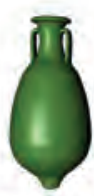

Dressel7_11

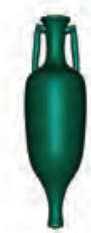

Dressel2_4_Iongue Dressel2_4_Courte
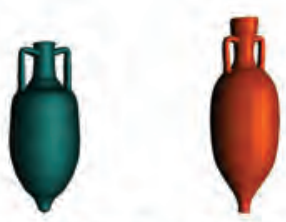

Pascual 1

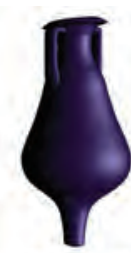

Beltran 2B

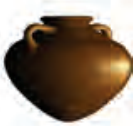

Py 4

Figure 3. A 3D representation of amphorae models used in the Venus project. The modeling process consisted of creating theoretical models and then implementing a decision support system that provides geometric parameters for the amphorae being studied.

measurements. To approximate these characteristics, we used a series of simple geometric primitives, which served as an interface between the photogrammetric measurements and the underlying model. For amphorae, we defined four measurement areas: rim, handle, belly, and base (see Figure 4). Using the least-square method, we fit a set of simple geometric primitives onto the measured points-for instance, a circle on the rim or belly points, or a line on the base point.

The decision support system. Photogrammetric measurements are highly incomplete (an object might be partially occluded or might have deteriorated). So, we used the Jess rule-based expert system (http://herzberg.ca.sandia.gov/jess) to determine the best strategy for providing the studied object's geometric parameters. The system started from the measurement process and handled the default data as defined in the theoretical models.

The expert system only performs geometric computation and is hidden behind the Arpenteur user interface. It's extremely useful to archaeologists because it helps fill the missing amphorae information with theoretical data. The resulting object is therefore based on a theoretical model, dimensioned by photogrammetric measurements.

\section{Working with the Models}

With the Arpenteur interface, the user (generally an archaeologist) can

- recognize the amphora type in the photographs,

- choose the amphora type (see Figure 3) in the interface combo box,

- measure a set of points in the zone where measurements are allowed (see Figure 4),

- add archaeological comments and observations,

- check consistency between observations and the theoretical model, and

- store a new instance in the database.

Afterward, the user can import the amphorae database into our virtual 3D environment, which we describe later.

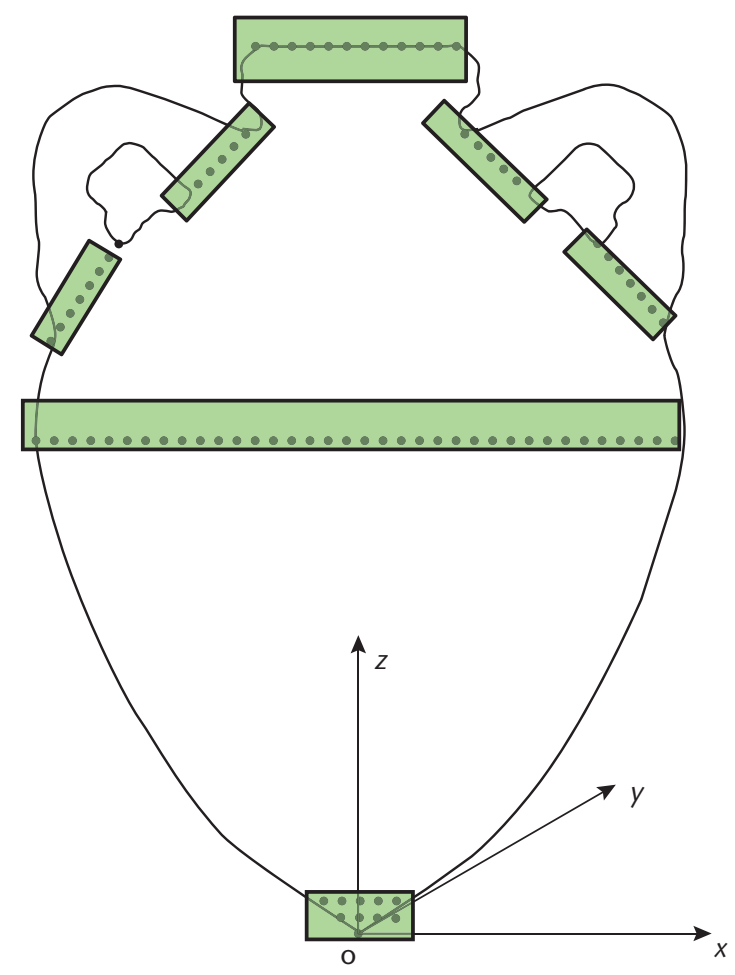

Figure 4. Potential photogrammetric-measurement locations for generating an amphora instance in the database. We defined four locations: rim, handle, belly, and base.

\section{The Models' Usefulness}

Accurate recording, modeling, and visualization of the individual amphorae provides the viewer with a first-class accurate digital reconstruction of the vessel's cargo as recorded at the time of survey. Our visualization tools have proven important for a number of tasks, such as identifying anomalies in the data. For example, because we could obtain details on demand and drill down to individual amphora data items, we could identify that one site surprisingly contained amphorae from very different epochs. Archaeologists could visualize various clusters of amphorae (in overview and zoomed-in formats) on the basis of parameters such as location, age, type, and state. So, they identified the Pianosa site as either a historical dumping ground for amphorae or a site where multiple vessels had 


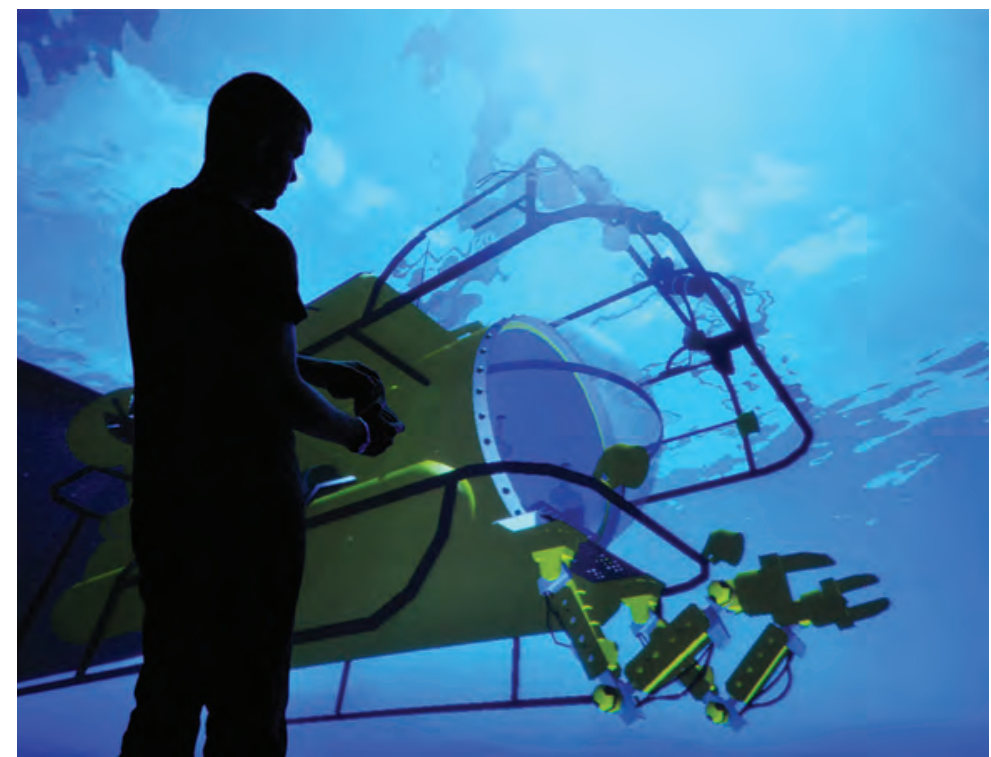

Figure 5. An archaeologist launches the virtual submarine to explore deepwater archaeological sites. After launching the submarine, the user can switch to a first-person perspective (see Figure 6).

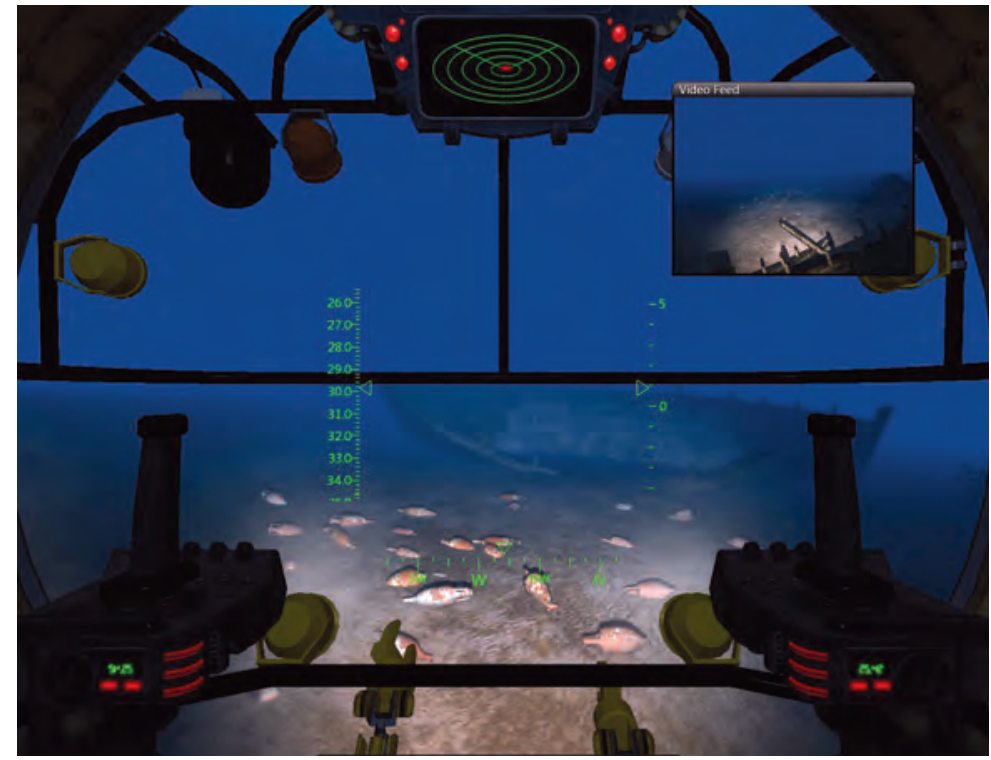

Figure 6. Venus-PD (Virtual Exploration of Underwater Sites-Public Demonstrator) lets the user pilot a virtual submersible down to accurate digital models of archaeological sites. This is a visualization of the Pianosa site. The shipwreck (see the inset) no longer exists; we modeled it using the recreated ship in Figure 7.

sunk (at different times), along with their cargos of amphorae.

\section{Combining the Data}

We integrated the Pianosa terrain data from the sonar bathymetry mission, the photogrammetric data for texture mapping, and the amphorae model database. ${ }^{3}$ At this point, this data resides in a relational database. Employing a set of Java tools, we can use this data to wrap objects from the database into a VRML representation or OpenSceneGraph data file.

This final output file contains a link to every amphora in the database via a PhP interface. This interface lets the user view, check, and modify the archaeological values relating to the amphorae. Of course, the user can still access all the raw data such as measuring points, photos, and photo orientation used to measure an artifact.

The precision for all the photographs was approximately $2 \mathrm{~cm}$, and the relative error was less than $5 \mathrm{~mm}$ when the signal was good. The absolute accuracy was approximately $40 \mathrm{~cm}$ (using the control points given by the acoustic measurement from the ROV).

\section{Visualizing the Data}

Scientists have successfully been using computer graphics for a number of years to improve our understanding of both offshore marine activities and land-based archaeological sites. ${ }^{4}$ However, the oil and gas industries have traditionally dominated marine visualization, focusing on activities such as pipeline operations and debris cleanup. ${ }^{5}$ Only limited research has dealt with underwater archaeological visualization.

We developed Venus-PD, our immersive public demonstrator, to bring interactive marine visualization to underwater archaeology and visualize data collected from Pianosa and other sites to generate an accurate first-person perspective of the entire dive process. Throughout the dive experience, the user maintains full control over the virtual submarine and can manipulate it with a full six degrees of freedom, using a commercially available game controller such as the XBox 360 wireless gamepad. Figure 5 shows an archaeologist launching the virtual submersible before diving to the Pianosa site. At the touch of a button, the user can switch to the first-person perspective and experience the dive from the cockpit (see Figure 6).

Venus-PD includes a storyboard feature triggered by certain events during the dive. For example, when the user finally arrives at the Pianosa site, the screen presents the wreck's history, including a photograph of a replica of the original trading vessel (see Figure 7). This feature has been useful for explaining to the general public the site's important elements and the Venus project's significance.

We developed Venus-PD using OpenSceneGraph, an open source, high-performance 3D graphics toolkit. Significant advances in graphics card technology have permitted real-time, perpixel rendering of the underwater site, including 
- realistic ocean surface rendering;

- depth of field and fogging (used for increased depth perception);

- silt effects;

- lighting effects (replicating the absorption and scattering of light rays as they travel through the water column onto the seabed); and

- underwater biological life, including fish and plants.

These special effects increase the pilot's sense of immersion and the virtual Pianosa site's authenticity. Consequently, when the user locates the Pianosa amphorae, he or she experiences an extremely accurate representation of the archaeological site as surveyed by the Venus team over the last three years. If the real site is ever destroyed, it's comforting to know that the 3D digital copy will continue to educate and captivate the general public.

$\mathrm{T}$ he Venus project ended in July 2009; it resulted in a series of best practices and procedures for collecting, storing, and visualizing underwater archaeological data. Interestingly, various visualization tools developed during the project proved more successful with the general public than with the archaeologists. However, younger archaeologists (for example, PhD students) expressed real enthusiasm for these tools. A comparative study based on a questionnaire shown to 24 underwater archaeologists, along with more information and free software, is available at www.venus-project.eu.

\section{Acknowledgments}

Venus was partially supported by the European Community under project Venus (Contract IST034924) of the Information Society Technologies Programme of the 6th Framework Programme for Research, Technology Development, and Demonstration. The authors are solely responsible for this article's content. It doesn't represent the opinion of the European Community, and the European Community isn't responsible for any use that might be made of data appearing therein. We acknowledge the work and contributions of all 11 Venus partners. We also acknowledge Epoch (European Network of Excellence in Open Cultural Heritage) for supporting the initial networking of the project members.

\section{References}

1. P. Chapman et al., "Venus, Virtual ExploratioN of Underwater Sites,” Proc. 7th VAST Int'l Symp. Virtual

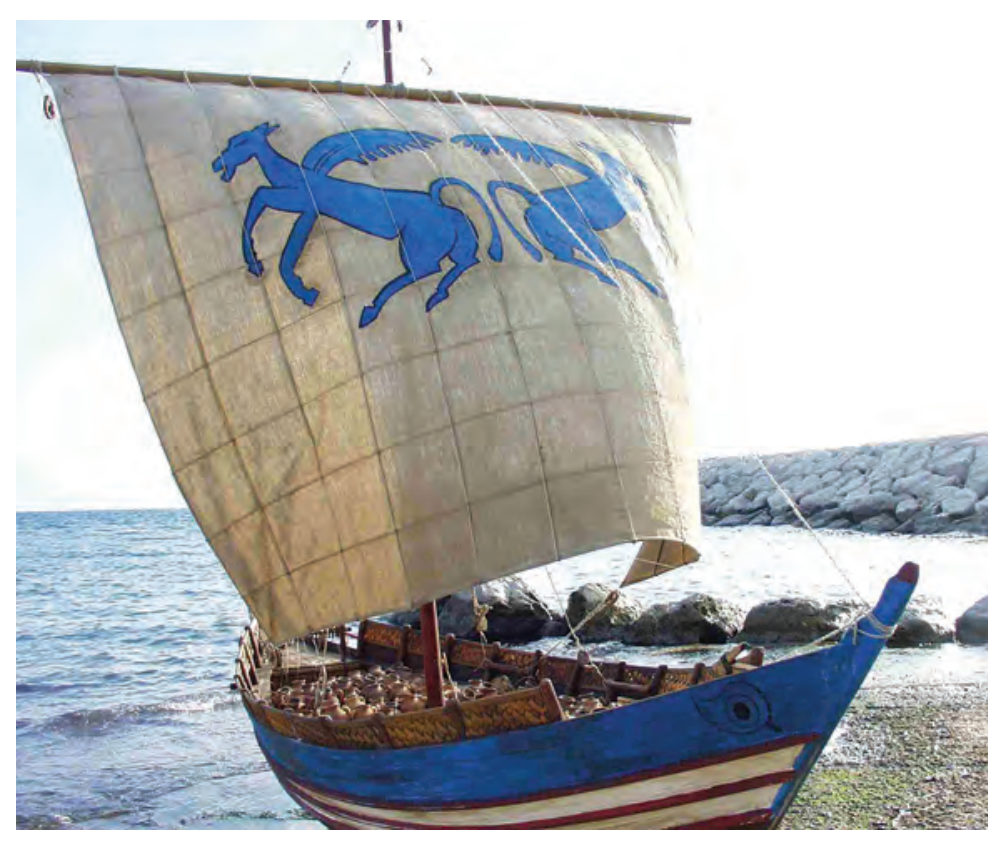

Reality, Archaeology, and Cultural Heritage, 2006, pp. 86-93.

2. Pierre Drap et al., "Underwater Cartography for Archaeology in the Venus Project," Geomatica: The J. of Geospatial Information Science, Technology, and Practice, vol. 62, no. 4, 2008, pp. 419-428.

3. P. Drap, J. Seinturier, and L. Long, "A Photogrammetric Process Driven by an Expert System: A New Approach for Underwater Archaeological Surveying Applied to the 'Grand Ribaud F' Etruscan Wreck," Proc. 2003 Conf. Computer Vision and Pattern Recognition Workshop, vol. 1, IEEE CS Press, 2003, p. 16.

4. E. Vote et al., "Discovering Petra: Archaeological Analysis in VR," IEEE Computer Graphics and Applications, vol. 22, no. 5, 2002, pp. 38-50.

5. P. Chapman et al., "Real-Time Visualization in the Offshore Industry," IEEE Computer Graphics and Applications, vol. 21, no. 4, 2001, pp. 6-10.

Paul Chapman is the deputy director of the Glasgow School of Art's Digital Design Studio. Contact him at paul@pixelbeans.net.

Kim Bale is a research assistant in the University of Hull's Department of Computer Science. Contact himat k.bale@hull.ac.uk.

Pierre Drap is a researcher at the Laboratoire des Sciences de l'Information et des Systèmes, in Marseille, France. Contact him at pierre.drap@lsis. org.

Contact department editor Theresa-Marie Rhyne at theresamarierhyne@gmail.com. Selected CS articles and columns are also available for free at http://ComputingNow.computer.org.
Figure 7. A recreated vessel similar to the Pianosa wreck. This vessel formed the basis for the shipwreck depicted in the inset in Figure 6. 
This article was featured in

\section{computing now}

For access to more content from the IEEE Computer Society, see computingnow.computer.org.

\section{- IEEE IEEE (D) computer society}

\section{Top articles, podcasts, and more.}
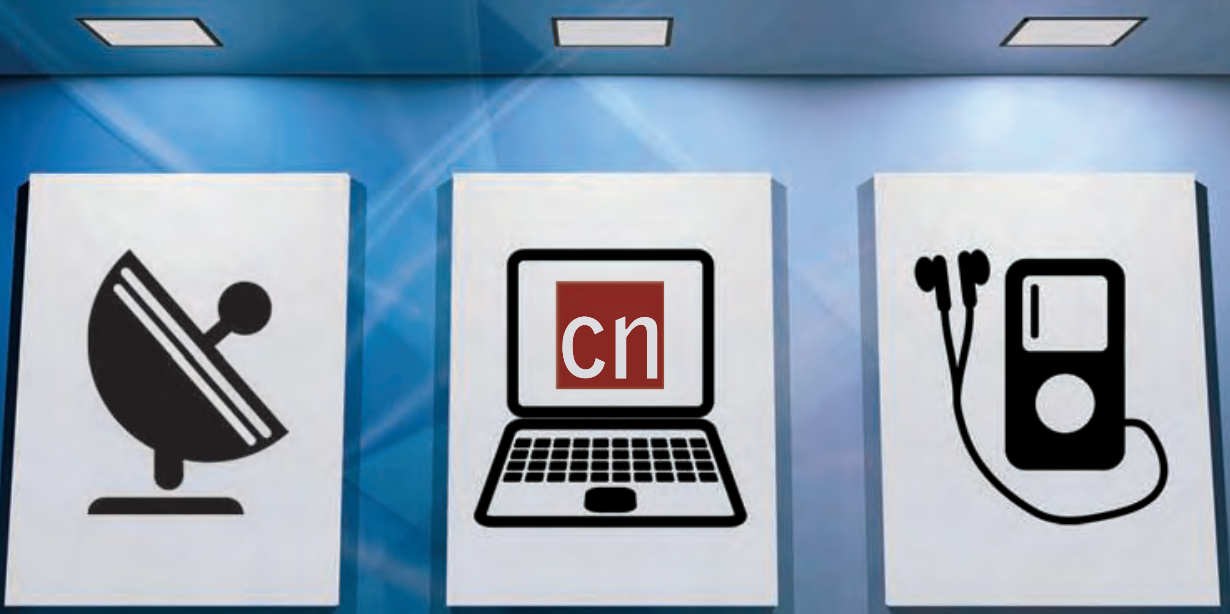